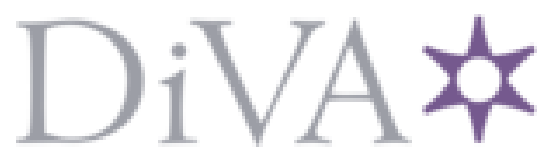

http://www.diva-portal.org

This is the published version of a paper presented at 1oth International Conference of Education, Research and Innovation.

Citation for the original published paper:

Ahlin, K., Mozelius, P. (2017)

Redesign and Evaluation of a Technology Enhanced Learning Environment for Thesis Supervision.

In: L. Gómez Chova, A. López Martínez and I. Candel Torres (ed.), ICERI2O17 PROCEEDINGS (pp. 636-643). Sevilla, Spain: IATED Academy International Conference of Education, Research and Innovation

N.B. When citing this work, cite the original published paper.

Permanent link to this version:

http://urn.kb.se/resolve?urn=urn:nbn:se:miun:diva-32099 


\title{
REDESIGN AND EVALUATION OF A TECHNOLOGY ENHANCED LEARNING ENVIRONMENT FOR THESIS SUPERVISION
}

\author{
Karin Ahlin, Peter Mozelius \\ Department of Computer and System Science, Mid Sweden University, Östersund
}

(SWEDEN)

\begin{abstract}
Thesis supervision is an important activity in higher education with Bachelor's and Master's theses mandatory parts of university programmes. In traditional education, thesis supervision has been a face-to-face activity, but today, both the student groups and the learning environments are blended. This study describes and discusses the design and implementation of a blended learning environment for a student group at Mid Sweden University. The research question that the study aims to answer is: Which are the important factors in the design of a course for undergraduate students, to facilitate supervision of thesis projects in a technology enhanced environment?
\end{abstract}

This study employed a Design science research strategy with three phases for design, implementation and evaluation of a blended learning environment during thesis supervision. For the first phase, design requirements were specified based on document studies and a literature review. In the second phase (first part), the created design requirements were implemented as an instance in the Moodle virtual learning environment. Second phase (second part), the implemented instance was used as the online part of a blended learning course for students writing their Bachelor's thesis. In the third phase an evaluation was carried out with an online questionnaire were students gave their opinions on course design and teaching and learning sessions.

Findings show that the learning outcomes were good and that the course aim and the learning objectives were clearly stated. Found important factors for a successful supervision were peer collaboration, multimodality, and technology enhanced interaction. Remaining challenges are to improve course content and to motivate students for research in the field of Informatics. Most surprising positive finding was that peer situation occurred informally, which deepen their knowledge for thesis writing and presentation.

Keywords: Thesis supervision, Technology enhanced learning, Blended learning, Blended synchronous learning, Virtual learning environment.

\section{INTRODUCTION}

During a university programme, a student's work with a mandatory thesis is probably the largest block of work that he or she will be assigned. In traditional education, thesis supervision was built around a series of face-to-face activities. Today there exists a rich variety of blended learning environments for thesis supervision and several universities have developed their own systems [1-3]. Except for the more flexible learning situation, a benefit of creating technology enhanced environments for thesis supervision is the possibility to decrease the supervisors' administrative workload. Another is to create a dynamic record of the supervision process [2, 4].

One of the most frequently cited reasons for implementing virtual learning environments is the possibility for more effective pedagogical practices, but without a careful design there is a risk for cognitive overload [5], with learners in a state of confusion [6] or with a feeling of loneliness and boredom [7]. Technology enhanced learning must, as all other educational settings, be designed with a human touch [8], where tools and media technology should support learners' various needs [9].

A blended learning environment should fundamentally be learner centred [10], but also provide channels for teacher-learner discussions and interaction [11]. Furthermore it seems important to care about students' identified need of feedback and guidance in online environments [12]. Finally, for a rather small department with limited resources the overall strategy ought to be a straightforward design following the guidelines suggested in the study by Fleming, Becker [13], building on low complexity, authenticity and adequate technical support. 
The aim of this study is to describe and discuss the implementation of an instructional design that supports student collaboration through peer reviews and discussions that has been described in research studies [1,3]. The main instructional design idea in this study is to enable students' collaboration and social presence to support quality learning outcomes and learner satisfaction [14].

\subsection{Research Question}

This study is based on the following research question: Which are the important factors in the design of a course for undergraduate students, to facilitate supervision of thesis projects in a blended synchronous learning environment?

\section{EXTENDED BACKGROUND}

The studied course is the Bachelor's Degree Project at the Department of Computer and Systems Science, Mid Sweden University (Miun). The course is held in the area of Information Systems, offered every semester, and is the last before students graduate. Previously, the course was held as a distance course, and it shifted to blended synchronous learning for the investigated semester. The course accommodates between 3 and 25 students. The purpose of the course is for the student to plan, conduct, and report a scientific study in the Information System's area. The students themselves choose their thesis area, such as artificial intelligence or web analysis. Their thesis must include a study where empirical material is collected, and the thesis is structured to include introduction, methodological description, theory, analysis, discussion, and conclusion. The student has to act as opponent at two seminars and at the defence seminar. There are several roles connected to the course: student, subject matter expert, instructors, supervisors, and examiner.

A course module, detailing course structure, tasks, expectations, and learning outcomes, is required for each course at Miun. Each semester the previous semester's course module is copied and manually modified or updated as wished by the instructors. The course module is based on Moodle, an open-source Information System, which is used worldwide for distance or campus learning. Implemented at Miun is a standard configuration, with a great number of functionalities. The instructors decide themselves which functionality to use, based on their own requirements. Facing the shift from distance to blended learning, the course module needed to be redesigned. The course module is central for the communication between the instructors and students, as well as among students. The communication is asynchronous, where Miun's configuration is set up to announce forum replies within half an hour. The department uses Adobe Connect and Skype for synchronous communication.

\subsection{Blended learning}

The use of blended learning environments has rapidly increased, and, as Garrison and Kanuka [15] observed, the shift to some kind of technology enhanced blended learning approach seems inevitable in higher education. Blended learning could broadly be defined as the convergence of Technology Enhanced Learning (TEL) and face-to-face education [10]. Despite some reported problems [6, 16], there exists a successful tradition of using tools and technology for distance education in sparsely populated rural areas; one example is Athabasca University in rural Canada [17].

The important main system for TEL as well as for blended learning is the virtual learning environment (VLE), where the given condition for this study is to design and implement a solution for the Moodle VLE [18]. TEL today, also subsumes the older term e-learning [19], which sometimes was used with a confusing variety of meanings [20]. At Miun, the blended learning is implemented as blended synchronous learning, meaning a mix of on-campus and distance students. In blended synchronous learning environments, remote students participate in face-to-face sessions through the use of richmedia synchronous technologies such as video conferencing systems and virtual worlds [21] .

\section{METHOD}

This study used Design Science as the overall strategy where an artefact was developed to solve a problem, as described by Hevner, March [22]. By definition, design science is about developing artefacts that address real-world problems. The development process is supposed to be iterative and incremental in its nature [23]. 
For the study at hand, the development was divided into three phases: definition of requirements, implementation of the artefact, and evaluation of it. The first step included reading documents, such as Mid Sweden University's website (Miun, 2017) to find the requirements at the University level, and a literature review to define the Technology Enhanced Learning's sub-categories. The second phase focused on implementation of the artefact; the last phase included evaluation of the implemented artefact, the course instance. Evaluation data was gathered from the students attending the course Bachelors' Degree Project at Mid Sweden University and analysed via the requirement categories.

\subsection{Development of the artefact}

The development of this study's artefact was conducted at the Department of Computer and Systems Science. Below, the three phases of (a) definition of the requirements, (b) implementation, and (c) evaluation are described.

\subsubsection{Definition of requirements}

Three levels of requirements were specified for the artefact: U-level, S-level and B-level. The U-level requirements are expressed in its values, defining a foundation for instructors. The S-level is a formalised and joint decision by all colleagues in the department, formally expressed through the statements of purpose, learning achievements, and content. The B-level requirements are based on a literature review, which initially was published as a standalone publication [24].

\subsubsection{Implementation of requirements}

The initial implementation of the course instance was done when the virtual learning environment (VLE) was adopted for use. This instance was based on the U-level, S-level, and B-level requirements and a VLE template for the department. Course teachers have some choices within the template and can decide specific content to address the various department-approved headlines. The U-level requirements are on a general level and permeate the overall course instance. These requirements are defined by the university, although individual instructors choose how to incorporate them throughout course experiences and expectations. The S-level requirements are developed by all faculty in the department and are founded in theory related to the various course sections. The syllabus is mainly constructed by the course instructors and formally approved by all department faculty. The B-level requirements were developed based on the literature review, mentioned above.

\subsubsection{Evaluation}

Up until the academic year in which this study took place, Miun's courses were evaluated in an automatic process, where the students answered the same questions for each course. The process was centralised in the sense that the surveys were sent out automatically, with no interference from the instructors. The standard Miun evaluation included 18 questions. The researchers determined that 15 questions (four of which were added by the instructors) would be utilised in this study. Recently, the instructors were given the possibility to add five closed questions, to be answered with a predetermined scale, and two open questions, to be answered in free text fields. For this study, the instructors added four new questions, to be answered with a scale, to the evaluation.

Questions were categorised at either of the levels of U-, S- or B-level. The number of questions at the University level is four; three scales and one free text field, and four scales and one free text field questions at the Syllabus level. Six learning questions on the B-level were sub-categorised by Learning outcomes and learner satisfaction, Collaboration and social presence, Instructional design and the teacher role, Multimodal overloading, and Course design.

\section{IMPLEMENTATION OF THE REQUIREMENTS}

As described in several research articles and books [23, 25], important main phases in Design science for the development of an artefact are the design, construction and evaluation phases. Design requirements are specified under section 4.1 , the actual implementation or construction phase is described under 4.2 and finally the evaluation process is presented in 4.3.

\subsection{Definition of the artefact}

The requirements are based on three various levels, the university level consisting of pre-determined requirements of higher education in Sweden, the syllabus and implementation of blended learning. 
Therefore, the intended requirement levels are: university, syllabus, and blended learning. The university level includes requirements based on Miun's values and policy documents for higher education, requirements on the syllabus level focuses are derived from the course syllabus, and requirements from the blended learning are evolved from the literature review.

\subsubsection{University level}

Outside of the general requirements as a government authority, such as legal requirements, objectivity, free opinion, efficiency and service, the core values at Miun are close relations, benefits, and curiosity. These values frame daily activities and meetings with the students and the surrounding world. Close relations refer to relations between student and instructor, research and higher education, as well as between higher education and working life. Engagement and accessibility result in an organisation with close relations. Benefits for students are expressed in terms of preparing them for their coming working life, where higher education is intended to contribute to the personal development of the students, their community involvement, critical thinking, and education. Curiosity is embraced as eagerness to learn and discover, to consider new aspects, share new influences and opinions, and used as a motivator to develop as an individual and a student.

\subsubsection{Syllabus level}

The requirements on the syllabus level are focused on how the student conducts a research project and what is included in the thesis. Detailed descriptions of how include parts such as: identifying and formulating relevant problem areas and research questions, and planning, realising, and analysing the content of an empirical study. The research focus is intended to be on the Information System's area, and is intended to generate knowledge in the field.

There are two levels of learning objectives in the syllabus; one is the individual level and the other is the group level. In this course, the group level needs special attention, because in blended synchronous learning these objectives must work for both campus and distance students. One of the two learning objectives on the group level high-lighted that students should be able to present their thesis work in both written and oral form to enable a scientific conversation. The other objective was that students should be able to carry out a critical review of their own and others' theses.

\subsubsection{Blended learning level}

This definition of requirements must consider the various roles in a blended learning environment for all involved stakeholders including students, supervisors, teachers and subject matter experts. Important requirements for the course design are:

Learning outcomes and learner satisfaction: To achieve good course outcomes, the design should primarily focus on learning outcomes $[26,27]$ and that a technology enhanced learning design should start by identifying the key learning outcomes $[27,28]$. Successful learning outcomes and learner satisfaction depend on students' active engagement, collaboration and social presence [12, 29].

Collaboration and social presence: To include interaction and social presence are important factors in blended learning environments [12] and there should also be channels for student - instructor and instructor - student interaction as well as multiple possibilities for student - student collaboration. In a study by So and Brush [11] it was pointed out that students with high perceptions of collaboration in the course activities also perceived a high social presence. Hence in virtual learning environments sometimes attending to neglected emotional support is a crucial factor to reduce students' sense of distance and loneliness in the online learning process. The recommendation is an instructional design that provides such socio-affective interaction [11].

Instructional design: There are many research articles with studies presenting various learning theories for blended learning. Some well-discussed and tested examples are constructivism, constructionism, connectivism or problem based learning, but the choice for this study is rather to focus on didactics and instructional design in a mix of ideas from various pedagogical models like it has been compiled by Anderson [17].

Teacher role: Several researchers have pointed out that teachers' and instructors' characteristics like attitude, teaching style, and responsiveness are important for the course outcomes [30]. Furthermore, it has been highlighted that instructor's teaching quality are affecting both students' social presence and their learning satisfaction [14]. Finally, most students have a need to feel confident that teachers' guidance and feedback to concerns, assessment outcomes should be swift and responsive [12]. 
Multimodal overloading: There exist research studies highlighting that students tend to be more socially engaged and satisfied with their learning with dynamic and interactive media formats $[9,16]$. This could be implemented with channels for asynchronous discussions and online facilitation, and with the use of audio and video files [31]. Picciano [9] claims that today's heterogeneous student groups have learners representing different generations, different personality types and different learning styles, motivating the combination of multiple approaches and multiple modalities. Later studies have questioned the idea of learning styles, but students with different backgrounds obviously have different study techniques and different needs of online support. A recommendation for design of online environments are to provide students with multiple possible paths through the course content, involving different media [27]. An implementation where multiple approaches and modalities are overloaded is costly and time consuming, but on the other hand also a design that can be seen as the best in a longer perspective.

\subsection{Implementation of the requirements}

The actual design was implemented in a multimodal mix of various media resources that were selected by their potential to fulfil the requirements and to facilitate students' learning process. All major changes were carried out by the authors and at the same time discussed by colleagues. As in all practical implementations, there was a need to pay attention to the existing context, in this case the Moodle VLE platform.

One way of implementing requirements was to align web-resources with video recordings enabled by the Camtasia studio software. This alignment with video was conducted with the didactic idea that students first should read about concepts, secondly listen to them, and thirdly discuss them. Another idea was to complement the course literature with web resources in related areas, such as guidelines for data analysis.

Introduced this semester were two group seminars in which all students had to present actual version of their thesis, peer-review another thesis, and the instructor peer-reviewed all theses for their actual group. The scheduled time slots were extended on several seminars due to vivid discussions. Outside of the formal seminars, various students met in informal additional peer-reviews.

\subsection{Evaluation}

Considering the U-level, the requirements are covered by the mandatory questions in the evaluation questionnaire's mandatory questions. In the same way, the S-level requirements were partly provided for in the mandatory questions. In contrary, several B-level requirements had to be mapped to additional tailor-made questions.

The added questions on S-level both measured the course content and the course activities and their support for the students' learning process. The answers to these questions were a grading scale from 1 - 5. With the same scale, the B-level requirement considering extended course material was covered. On the more complex B-level, there was a need for open ended questions. Firstly, one question aimed to investigate the students' interest in a further research career, a question that also have relevance for the U-level. Secondly, what we see as the most interesting question on course design, has invited to a dialogue with instructors and other thesis' writers.

\section{RESULTS AND DISCUSSIONS}

Regarding the U-level, the overall impression was high, especially concerning how students were met on equal terms (4.8 out of 5.0). A high average was seen for the question regarding the supervisors' availability and time spent on the students (4.4/5.0). Lower results (3.6/5.0) were seen, with high standard deviation, for the question about to what degree the acquired knowledge would be useful in their future working life.

On the S-level, the average impression was a bit lower, mostly depending on the answers connected to the usability of the course material on the VLE (3.0/5.0). This grade was followed by 3.7/5.0 for how well the course activities supported the students in the planning, conducting, and presenting their thesis. The highest grade was given the question about the course content in relation to the learning objectives (4.0/5.0).

Considering the B-level, the average impression is even lower although in the same class. The instructor-led classes were rated for learning support at 2.9/5.0 with small deviation, followed by 
3.3/5.0 for the course literature's support of learning. Moodle as a platform for learning support was rated 3.3 out of 5.0. The authors' impression of this rating is that students were keener on using Skype alone as the preferred support for learning.

However, students showed more appreciation for the blended synchronous design in the open-ended answers. Especially, on the question whether the design invited to a dialogue with instructors and other thesis writers. Some answers from the students were: "Good idea with small groups", "Good dialogues with the supervisors", and "It came naturally through an ongoing dialogue with the supervisors about the thesis writing. Good dialogue between thesis writers during the peer-review." Collaboration was appreciated, both considered student - instructor collaboration and peer collaboration, where the later contributed most to the learning and learning outcomes. Findings also showed that both types of interaction are strongly dependent on the technology enhanced tools.

There were mixed opinions among the students whether any particular course moment stimulated future research. Such opinions ranged from the quite negative: "Information Systems as research field is not of interest to me," to more specific opinions describing course moments such as presentations and peer-reviews as stimulating future research. Students' opinions were that part of the course content was hard to grasp and the new audio-visual components were appreciated.

Looking across the course as one unit, the three levels are inter-related and integrated and the borders are not always clear. In the results, there are themes with relations across all the levels. The main emergent themes were: (1) peer collaboration, (2) multimodality, and (3) technology enhanced interaction. These themes are closely related to each other. Our main finding is the students' appreciation of peer collaboration and supervision interaction, built on TLE and multimodality. Compared to earlier course batches, the number of mandatory interactive occasions was higher in this implementation, which seems to have had the side effect of increasing the number of spontaneous informal peer-interactions. Although, there is an upper limit for the number of occasions, exemplified by one student: "I would like daily meetings, but it is understandable if this is not feasible for the supervisors." The idea of running a course a flexible way through more frequent meetings is interesting but not really doable and it does not really harmonise with the learning objectives.

There are several ways to interpret the findings. One is that we have designed the course in a way that fulfils the U- and S-level requirements but with further development needed for the B-level, synthesised in the scores. Another way to interpret this, is that the actions for the B-level are a step in the right direction, but not implemented to fully meet the students' needs. However, a fundamental principle in design science is that development is an iterative process [23, 25]. This first step has given some initial knowledge on how to redesign a blended synchronous learning environment for thesis supervision, but there would for several reasons be interesting to further this implementation on the Blevel.

\section{CONCLUSIONS}

To answer the research question, we found important factors for supervision of thesis projects in a blended synchronous learning environment are: 1) to enable peer collaboration, 2) to present essential course concepts in various modalities, and 3) that technology enhances the interaction between instructors and learners.

To conclude, no obvious recipe for a successful thesis supervision in a blended synchronous learning environment was found. Particular course parts that have been appreciated by some students seem less important to other students. This might be summarised by a quote from one of the students: "No particular moment, since my opinion that all moments have been part of a whole - the thesis work. I think it is hard to raise a strong motivation for further research at the end of the last semester. The entire semester has a clear focus on research and I am keener on to work practically with system development. A problem can be that this last semester has contained so much research compared to earlier semesters. On the other hand, I understand the set-up and see no reasons for major changes."

\section{REFERENCES}

[1] MacKeogh K, editor Supervising undergraduate research using online and peer supervision. 7th International Virtual University Conference; 2006; Bratislava 14-15 December 2006. Technical University Bratislava: Bratislava. 
[2] Beer MD, Mason RB. Using a blended approach to facilitate postgraduate supervision. Innovations in Education and Teaching International. 2009;46(2):213 - 26.

[3] Hansson $\mathrm{H}$, editor How to produce quality theses at universities in a large scale: SciPro IT system-Supporting the Scientific Process. Frontiers in Education Conference; 2014.

[4] Mason RO, McKenney JL, Copeland DG. Developing an Historical Tradition in MIS Research. MIS Quarterly. 1997;21 (3):257-78.

[5] Graham CR. Blended learning systems. The handbook of blended learning, 3-21. 2006.

[6] Hara N, Kling R. Students' distress with a web based distance education course: an ethnographic study of participants' experiences. Information, Communication, and Society 3. 2000:557 - 79.

[7] Brown KM. The role of internal and external factors in the discontinuation of off-campus students. Distance Education 1996;17(44 - 71).

[8] Keller J, Suzuki K. Learner motivation and e-learning design: A multinationally validated process. Journal of Educational Media. 2004;29(3):229 - 39.

[9] Picciano AG. Blending with purpose: The multimodal model. Journal of asynchronous learning networks 2009;13(1):7 - 18.

[10] Watson J. Blended Learning: The Convergence of Online and Face-to-Face Education. Promising Practices in Online Learning. North American Council for Online Learning 2008.

[11] So HJ, Brush TA. Student perceptions of collaborative learning, social presence and satisfaction in a blended learning environment: Relationships and critical factors. Computers \& Education. 2008;51(1):318 - 36.

[12] Garner R, Rouse E. Social presence-connecting pre-service teachers as learners using a blended learning model. Student Success 2016;7(1):25 - 36.

[13] Fleming J, Becker K, Newton C. Factors for successful e-learning: does age matter? Education+ Training 2017;59(1):76 - 89.

[14] Kim J, Kwon Y, Cho D. Investigating factors that influence social presence and learning outcomes in distance higher education. Computers \& Education. 2011;57(2):1512 - 20.

[15] Garrison DR, Kanuka H. Blended learning: Uncovering its transformative potential in higher education. The internet and higher education. 2004;7(2):95 - 105.

[16] Chen WS, Yao AYT. An Empirical Evaluation of Critical Factors Influencing Learner Satisfaction in Blended Learning: A Pilot Study. Universal Journal of Educational Research. 2016;4(7):1667 $-71$.

[17] Anderson T. The theory and practice of online learning: Athabasca University Press. ; 2008.

[18] Dougiamas M. Moodle: A virtual learning environment for the rest of us. TESL-EJ, 8(2), 1-8 2004;8(2):1 - 8.

[19] Kirkwood A, Price L. Technology-enhanced learning and teaching in higher education: what is 'enhanced' and how do we know? A critical literature review. Learning, media and technology. 2014;39(1):6 - 36.

[20] Guri-Rosenblit S, Gros B. E-learning: Confusing terminology, research gaps and inherent challenges. International Journal of E-Learning \& Distance Education. 2011;25(1).

[21] Bower M, Dalgarno B, Kennedy GE, Lee MJ, Kenney J. Design and implementation factors in blended synchronous learning environments: Outcomes from a cross-case analysis. Computers \& Education. 2015;86:1 - 17.

[22] Hevner AR, March ST, Park J, Ram S. Design Science in Information Systems Research MIS Quarterly. 2004;28(1):75-105.

[23] Johannesson P, Perjons E. An introduction to design science. Springer; 2014. 
[24] Mozelius P, Hettiarachchi E. Critical Factors for Implementing Blended Learning in Higher Education. International Journal of Information and Communication Technologies in Education (ICTE) 2017.

[25] Hevner AR. A three cycle view of design science research. Scandinavian journal of information systems, 19(2), 4. . Scandinavian Journal of Information Systems. 2007;19(2):4.

[26] Alammary A, Sheard J, Carbone A. Blended Learning in Higher Education: Three Different Design Approaches Australasian Journal of Educational Technology. 2014;30(4):440 - 54.

[27] Shand K, Farrelly SG, Costa V, editors. Principles of course redesign: A model for blended learning. In Proceedings of Society for Information Technology \& Teacher Education International Conference 2016; 2016.

[28] Garrison DR, Vaughan ND. Blended learning in higher education: Framework, principles, and guidelines. San Francisco, CA, US: Jossey-Bass; 2008.

[29] Parker J, Maor D, Herrington J. Authentic online learning: aligning learner needs, pedagogy and technology. Issues in Educational Research. 2013;23(2):227 - 41.

[30] Al-Busaidi KA. Learners' Perspective on Critical Factors to LMS Success in Blended Learning: An Empirical Investigation. CAIS. 2012;30(2).

[31] Kwona O, Leea N, Shinb B. Data quality management, data usage experience and acquisition intention of big data analytics International Journal of Information Management 2014;34:387 94. 